Article

\title{
Sensitivity Analysis in a Complex Marine Ecological Model
}

\section{Marcos D. Mateus * and Guilherme Franz}

MARETEC, Instituto Superior Técnico, Universidade de Lisboa, Av. Rovisco Pais, Lisboa 1049-001, Portugal; E-Mail: guilherme.franz@tecnico.ulisboa.pt

* Author to whom correspondence should be addressed; E-Mail: marcos.mateus@tecnico.ulisboa.pt; Tel.: +351-21-841-9436.

Academic Editor: Y. Jun Xu

Received: 16 January 2015 / Accepted: 19 April 2015 / Published: 6 May 2015

\begin{abstract}
Sensitivity analysis (SA) has long been recognized as part of best practices to assess if any particular model can be suitable to inform decisions, despite its uncertainties. SA is a commonly used approach for identifying important parameters that dominate model behavior. As such, SA address two elementary questions in the modeling exercise, namely, how sensitive is the model to changes in individual parameter values, and which parameters or associated processes have more influence on the results. In this paper we report on a local SA performed on a complex marine biogeochemical model that simulates oxygen, organic matter and nutrient cycles $(\mathrm{N}, \mathrm{P}$ and $\mathrm{Si})$ in the water column, and well as the dynamics of biological groups such as producers, consumers and decomposers. SA was performed using a "one at a time" parameter perturbation method, and a color-code matrix was developed for result visualization. The outcome of this study was the identification of key parameters influencing model performance, a particularly helpful insight for the subsequent calibration exercise. Also, the color-code matrix methodology proved to be effective for a clear identification of the parameters with most impact on selected variables of the model.
\end{abstract}

Keywords: biogeochemical modeling; complex models; sensitivity analysis; parameter perturbation 


\section{Introduction}

Sensitivity analysis (SA) can be basically described as the process to evaluate the contribution of input parameters to model behavior. Several parameters in ecosystem models represent specific process coefficients that are only measured with difficulty (if possible at all). As a consequence, there are uncertainties related with the parameterization and the nonlinearity of interactions within the model. This raises two basic questions: (a) how sensitive is the model to changes in individual parameter values; and (b) which parameters or associated processes have more influence on specific output variables? Answering the first question may reveal which parameters have more influence on the model and need more attention. The answer to the second question will help to understand the simulated system.

Performing a SA is an effective way to answer these questions and assess model performance [1-5], thus justifying its widespread use to quantitatively assess the influence of parameters in model performance, and identify those having the most significant impact on the results [6-12]. In complex models with a significant number of parameters, the SA may help in the selection of the most relevant parameters for the calibration process $[4,7,13,14]$.

Sometimes the large number of input values in the habitual "one at a time" SA perturbation method requires excessive computation time [14-16]. Also, it leads to serious difficulties in visualizing the results in a comprehensive manner, especially in complex ecosystem models with dozens of parameters. To avoid a sensitivity matrix with numerous columns or rows, some proposed methodologies do not analyze single parameters, but rather clusters of related parameters in group-collecting sensitivity analysis, reducing the total amount of required variations by at least a factor 1/9 [17]. Other approaches, such as metamodeling, link model inputs to the output through a known relationship, emulating the original model but with less computational demands [10,18]. Despite all the advantages of such SA tests, one of the drawbacks is that it can mask the importance of individual parameters in model performance, providing instead a black-box response for the effect of individual parameters [19].

The aim of this paper is to perform a SA on a complex marine biogeochemical model that reproduces the dynamics of living groups (producers, consumers and decomposers), main nutrients $(\mathrm{N}, \mathrm{P}$ and $\mathrm{Si}$ ), oxygen and several pools of organic matter. We have used a schematic mesocosm application to prevent any influence of physical transport processes on the outcome of the model. To simplify the analysis, we have developed a color-code matrix to visualize the results of the SA. With this study we intend to identify key parameters influencing model performance, to focus on their variation in the subsequent calibration process.

\section{Model and Methods}

A process-oriented zero-dimensional ecological model (MOHID-Life [20]) is applied to simulate biogeochemical constituents in a virtual mesocosm. The choice of a zero-dimensional model application, instead of a real case application, is justified because it avoids a substantial increase in model run time. Also, it guarantees that only ecological processes are responsible for the change in the state-variable over time, by eliminating the effect of transport on the state-variables. The only physical process considered in the simulations is the sinking of particulate organic matter. MOHID-Life 
consists of a series of coupled first-order differential equations representing the major biogeochemical processes influencing the water quality, as well as the dynamic of several groups of primary and secondary producers, the microbial loop, nutrient recycling and oxygen dynamics. MOHID-Life is a complex model that accounts for the cycles of carbon, nitrogen, phosphorus, silica and oxygen. A detailed description of the model options and philosophy, as well as its parameterization, has been previously described and the values of the parameters tested here have been derived from these studies $[20,21]$.

The flexible parameterization of the model allows configuration of different degrees of complexity, by reducing or increasing the number of phytoplankton and zooplankton groups. So, to reduce the volume of results generated by the runs, and aiming at simplicity in the analysis, the reference simulation for this study is simplified by considering only one producer (diatoms) and one consumer (microzooplankton). Because the model philosophy is built on the concept of a Generic Type Model [20], this simplification in the application still allows assessing the importance of parameters, since the model uses the same code for all groups of producers and for consumer.

A reference run is used to provide the benchmark results for the parameter sensitivity analysis (see Section 2.3). The results of the sensitivity analysis are classified by distinguishing model parameters with a qualitatively different effect on the outcome of the simulation. The effect of single parameter variation on model performance is analyzed by singly and sequentially altering the standard value of each parameter with up- and down-variations of $10 \%$ in a series of separate runs, while holding all other terms constant. A raised and lowered 10\% parameter perturbation is frequently adopted $[15,22,23]$, hence its use in the present study.

\subsection{Sensitivity Index}

The choice of a sensitive index varies significantly in the literature [1,10,24,25]. From all the indexes available to quantify parameter sensitivity, we chose one able to quantify normalized sensitivity, but with the capacity to reveal up (positive) and down (negative) variation. The choice of index was based on its simplicity, and directly related to the objective of knowing the influence of any given parameter on the outcome of the simulation, i.e., the impact of a parameter and the nature of variation in the results.

Normalized sensitivity, $S_{(p)}$, is defined as the relative change in model output divided by the relative change in the parameter value. It is calculated as:

$$
S_{(p)}=\frac{\left(V_{(p)}-V_{s}\right) / V_{s}}{\left(p-p_{s}\right) / p_{s}}
$$

where all variables with an $S$ in the lower index represent standard case values $\left(V_{s}\right.$ the value of a given variable for the standard case with parameter $p_{s}$ ), and $V_{(p)}$ is the value for the case when the parameter is given the value $p$. As an example, to evaluate the impact of a negative perturbation $(-10 \%)$ of the parameter bio_si_diss on silicate concentration, we would have $p_{s}=0.01$ and $p=0.009$, and the respective model results for each parameter value, $V_{s}=3.07$ and $V_{(p)}=2.85$, respectively. In this particular case, $S_{(p)}=0.071$. 
This method is proposed by Fasham et al. [26] and adopted in other studies (e.g., [23,27]). According to this sensitivity index, a negative parameter perturbation (10\% below) with a negative index result means a positive perturbation in the end result of a given property (meaning a higher end value compared with the reference run value), whereas a positive index result means a negative perturbation in the result (a lower end value compared with the reference run). Conversely, a positive parameter perturbation ( $10 \%$ above) will give a negative index result if a negative end result is achieved, and a positive index result with a positive end result.

The degree of model sensitivity towards any given parameters can be defined as sensitive $(S>0.1$, meaning a change of more than $1 \%$ in the result when compared with the reference value), highly sensitive $(S>1$, meaning a change of more than 10\%), and extremely sensitive $(S>10$, meaning a change of more than $100 \%$ ). Whenever $S<0.1$, it can be said that the model is not sensitive to that parameter. However, it must be kept in mind that the bias achieved by omitting some variations is a frequent or potential error that might occur in a systematic SA. In addition, it is difficult to define the magnitude of parameter perturbation avoiding non-realistic values, but at the same time covering the actual range of the parameter [26].

\subsection{Variables of Interest}

Not all state-variables were selected to monitor the sensitivity of parameters. This choice relied on the assumption that an excessive number of state-variables would compromise the comprehensibility of the analysis. The biomass of functional groups, concentration of nutrients and labile-DOC (DOMl), and chlorophyll content in phytoplankton were selected as sensitivity indicators (Table 1), mostly because they correspond to properties for which field data is more frequently available. The phytoplankton carbon content to bacterioplankton carbon content ratio $\left(\mathrm{P}_{\mathrm{c}}: \mathrm{B}_{\mathrm{c}}\right)$ was set to evaluate the varying microbial community composition in response to different parameters values.

Table 1. Selected variables to assess model sensitivity.

\begin{tabular}{ccc}
\hline Symbol & Description & Initial Value \\
\hline $\mathrm{P}_{\mathrm{c}}$ & Producers biomass & $1 \mathrm{mg} \cdot \mathrm{C} \cdot \mathrm{m}^{-3}$ \\
$\mathrm{Z}_{\mathrm{c}}$ & Consumers biomass & $0.5 \mathrm{mg} \cdot \mathrm{C} \cdot \mathrm{m}^{-3}$ \\
$\mathrm{~B}_{\mathrm{c}}$ & Decomposer biomass & $1 \mathrm{mg} \cdot \mathrm{C} \cdot \mathrm{m}^{-3}$ \\
$\mathrm{NH}_{4}$ & Ammonium concentration & $4 \mathrm{mmol} \cdot \mathrm{N} \cdot \mathrm{m}^{-3}$ \\
$\mathrm{NO}_{3}$ & Nitrate concentration & $10 \mathrm{mmol} \cdot N \cdot \mathrm{m}^{-3}$ \\
$\mathrm{PO}_{4}$ & Phosphate concentration & $1 \mathrm{mmol} \cdot \mathrm{P} \cdot \mathrm{m}^{-3}$ \\
$\mathrm{Si}$ & Silicate concentration & $6 \mathrm{mmol} \cdot \mathrm{Si} \cdot \mathrm{m}^{-3}$ \\
$\mathrm{Chla}$ & Chlorophyll concentration & $0.01 \mathrm{mg} \cdot \mathrm{C} \cdot \mathrm{m}^{-3}$ \\
$\mathrm{DOMl}$ & Labile DOM concentration & $1 \mathrm{mg} \cdot \mathrm{C} \cdot \mathrm{m}^{-3}$ \\
$\mathrm{P}_{\mathrm{c}}: \mathrm{B}_{\mathrm{c}}$ & Producers-decomposer ratio & 1 \\
\hline
\end{tabular}

\subsection{Simulations Runs}

The model was applied to a virtual mesocosm corresponding to a schematic reservoir with $3 \times 3 \times 5$ square cells with $1 \mathrm{~m}$ each. A spin-up period of 16 months was used to stabilize the model, after which the SA simulations run for 3 months (May to July). The long spin-up period aimed 
at stabilizing the model after the "chaotic" oscillations characteristic from the first year run. The standard model parameterization used in the simulations is presented in Table 2 to Table 5, and have been taken from previous studies [20,21]. The initial values for the properties addressed in the SA are provided in Table 1. Environmental conditions used in the model forcing are shown in Figure 1. A schematic water temperature time-series was used and solar radiation corresponds to conditions representative for mid-latitudes in the northern hemisphere. The term "variable" is loosely used throughout the sensitivity analysis discussion because, with the exception of $\mathrm{P}_{\mathrm{c}}$ : $\mathrm{B}_{\mathrm{c}}$, the remaining correspond to state-variables in model.

Table 2. List of parameters for Producers (diatoms).

\begin{tabular}{|c|c|c|c|}
\hline Parameter & Description & Reference Value & Units \\
\hline min_nc_ratio & Minimum N:C ratio & 0.006284 & $\mathrm{mmol} \cdot N \cdot(\mathrm{mg} \mathrm{C})^{-1}$ \\
\hline max_nc_ratio & Maximum $\mathrm{N}: \mathrm{C}$ ratio & 0.0251 & $\mathrm{mmol} \cdot N \cdot(\mathrm{mg} \mathrm{C})^{-1}$ \\
\hline min_pc_ratio & Minimum P:C ratio & 0.000393 & $\mathrm{mmol} \cdot P \cdot(\mathrm{mg} \mathrm{C})^{-1}$ \\
\hline max_pc_ratio & Maximum $\mathrm{P}: \mathrm{C}$ ratio & 0.001572 & $\mathrm{mmol} \cdot P \cdot(\operatorname{mg} C)^{-1}$ \\
\hline max_chln_ratio & Maximum Chl:N ratio & 3 & $\mathrm{mg} \cdot C h l \cdot(\operatorname{mmol} N)^{-1}$ \\
\hline chl_degrad_rate & Chlorophyll degradation rate & 0 & day $^{-1}$ \\
\hline alpha_chl & Initial slope of the photosynthesis-light curve & 3.0025 & $\mathrm{mg} \cdot C \cdot \mathrm{m}^{2}(\mathrm{mg} C h l \cdot \mathrm{W} \cdot \mathrm{d})^{-1}$ \\
\hline affinity_nh4 & Affinity for $\mathrm{NH}_{4}$ (uptake rate) & 0.0025 & $(\mathrm{mg} C)^{-1} \cdot \mathrm{m}^{-3} \cdot \mathrm{day}^{-1}$ \\
\hline affinity_no3 & Affinity for $\mathrm{NO}_{3}$ (uptake rate) & 0.0025 & $(\mathrm{mg} C)^{-1} \cdot \mathrm{m}^{-3} \cdot \mathrm{day}^{-1}$ \\
\hline affinity_po4 & Affinity for $\mathrm{PO}_{4}$ (uptake rate) & 0.0025 & $(\mathrm{mg} C)^{-1} \cdot \mathrm{m}^{-3} \cdot \mathrm{day}^{-1}$ \\
\hline exu_nut_stress & Exudation under nutrient stress & 0.05 & Dimensionless \\
\hline exc_dom_sl_frac & $\begin{array}{l}\text { Excreted DOM fraction diverted } \\
\text { to semi-labile pool }\end{array}$ & 0.4 & Dimensionless \\
\hline max_assimil & Maximum assimilation rate & 2.5 & day $^{-1}$ \\
\hline max_store_fill & Maximum rate of storage filling & 1 & day $^{-1}$ \\
\hline min_lysis & Minimum lysis rate & 0.05 & day $^{-1}$ \\
\hline mort_dom_sl_frac & DOM fraction diverted to semi-labile pool & 0.4 & Dimensionless \\
\hline ref_temp & Reference temperature & 30 & ${ }^{\circ} \mathrm{C}$ \\
\hline rel_excess_si & Release rate of excess silicate & 1 & day $^{-1}$ \\
\hline resp_basal & Basal respiration rate & 0.15 & day $^{-1}$ \\
\hline resp_frac_prod & Respired fraction of production & 0.1 & Dimensionless \\
\hline sedim_min & Minimum sedimentation rate & 0 & $\mathrm{~m} \cdot \mathrm{day}^{-1}$ \\
\hline sedim_nut_stress & Nutrient stress sedimentation rate & 5 & $\mathrm{~m} \cdot \mathrm{day}^{-1}$ \\
\hline si_uptake_ks & Silicate uptake Michaelis constant & 0.3 & $\mathrm{mmol} \cdot \mathrm{Si} \cdot \mathrm{m}^{-3}$ \\
\hline nut_stress_thresh & Exudation under nutrient stress & 0.7 & Dimensionless \\
\hline
\end{tabular}

Table 3. List of parameters for consumers (microzooplankton).

\begin{tabular}{clcl}
\hline Parameter & Description & Reference Value & Units \\
\hline max_nc_ratio & Maximum N:C ratio & 0.0167 & $\mathrm{mmol} \cdot N \cdot(\mathrm{mg} C)^{-1}$ \\
max_pc_ratio & Maximum P:C ratio & 0.00185 & $\mathrm{mmol} \cdot P \cdot(\mathrm{mg} \mathrm{C})^{-1}$ \\
min_nc_ratio & Minimum N:C ratio & 0.015 & $\mathrm{mmol} \cdot N \cdot(\mathrm{mg} \mathrm{C})^{-1}$ \\
\hline
\end{tabular}


Table 3. Cont.

\begin{tabular}{cccc}
\hline Parameter & Description & Reference Value & Units \\
\hline min_pc_ratio & Minimum N:C ratio & 0.0017 & $\mathrm{mmol} \cdot P \cdot(\mathrm{mg} \cdot C)^{-1}$ \\
excre_up_frac & Excreted fraction of uptake & 0.5 & Dimensionless \\
mort_o2_dep & Oxygen-dependent mortality rate & 0.25 & day $^{-1}$ \\
mort_pom_frac & Fraction of excretion to POM & 0.5 & Dimensionless \\
mort_rate & Temperature-independent mortality rate & 0.05 & $\mathrm{day}^{-1}$ \\
o2_ks & Oxygen half saturation constant & 0.25 & $\mathrm{mg} \cdot O_{2} \cdot 1^{-1}$ \\
ref_temp & Reference temperature & 20 & ${ }^{\circ} \mathrm{C}$ \\
rest_resp_@10c & Rest respiration & 0.02 & $\mathrm{day}^{-1}$ \\
assimil_effic & Assimilation efficiency & 0.5 & Dimensionless \\
max_spec_up_@10c & Maximum specific uptake & 1.2 & day $^{-1}$ \\
graz_up_ks & Half saturation value for uptake & 40 & $\mathrm{mg} \cdot C \cdot \mathrm{m}^{-3}$ \\
p_graz_avail & Availability of prey & 0.9 & Dimensionless \\
\hline
\end{tabular}

Table 4. List of parameters for decomposer (bacterioplankton).

\begin{tabular}{|c|c|c|c|}
\hline Parameter & Description & Reference Value & Units \\
\hline min_nc_ratio & Minimum $\mathrm{N}: \mathrm{C}$ ratio & 0.016652 & $\mathrm{mmol} \cdot N \cdot(\mathrm{mg} \cdot C)^{-1}$ \\
\hline max_nc_ratio & Maximum $\mathrm{N}: \mathrm{C}$ ratio & 0.01972 & $\mathrm{mmol} \cdot N \cdot(\mathrm{mg} \cdot \mathrm{C})^{-1}$ \\
\hline min_pc_ratio & Minimum P:C ratio & 0.001096 & $\mathrm{mmol} \cdot P \cdot(\mathrm{mg} \cdot C)^{-1}$ \\
\hline max_pc_ratio & Maximum P:C ratio & 0.001665 & $\mathrm{mmol} \cdot P \cdot(\mathrm{mg} \cdot C)^{-1}$ \\
\hline ass_effic & Assimilation efficiency & 0.3 & Dimensionless \\
\hline ass_effic_low_o2 & Assimilation efficiency at low oxygen & 0.2 & Dimensionless \\
\hline dens_de-p_mort & Density-dependent mortality rate & 0.5 & day $^{-1}$ \\
\hline lys_ref_con & Mortality density dependent concentration & 100 & $\mathrm{mg} \cdot C \cdot \mathrm{m}^{-3}$ \\
\hline max_spec_up_@10c & $\begin{array}{l}\text { Maximum specific uptake at reference } \\
\text { temperature }\end{array}$ & 5 & day $^{-1}$ \\
\hline dom_up_ks & Half saturation constant for DOM uptake & 10.6 & $(\mathrm{mg} \cdot C)^{-1} \cdot \mathrm{m}^{-3}$ \\
\hline mort_dom_sl_frac & Fraction of DOM to semi-labile pool & 0.2 & Dimensionless \\
\hline mort_pom_frac & $\begin{array}{c}\text { Fraction of mortality products to particulate } \\
\text { organic matter }\end{array}$ & 0.4 & Dimensionless \\
\hline mort_rate & Density-independent mortality rate & 0.05 & day $^{-1}$ \\
\hline $\mathrm{o} 2 \_\mathrm{ks}$ & Oxygen half saturation constant & 0.01 & $\mathrm{mmol} \cdot \mathrm{O}_{2} \cdot \mathrm{m}^{-3}$ \\
\hline o2_low_ass_efic & Assimilation efficiency at low oxygen & 1.6 & $\mathrm{mmol} \cdot \mathrm{O}_{2} \cdot \mathrm{m}^{-3}$ \\
\hline rest_resp_@-10c & Rest respiration at reference temperature & 0.01 & day $^{-1}$ \\
\hline ref temp & Reference temperature & 30 & ${ }^{\circ} \mathrm{C}$ \\
\hline po4_ks & Affinity for $\mathrm{PO}_{4}$ (uptake rate) & 0.0025 & $(\mathrm{mg} \cdot C)^{-1} \cdot \mathrm{m}^{-3} \cdot$ day $^{-1}$ \\
\hline $\mathrm{nh} 4 \_\mathrm{ks}$ & Affinity for $\mathrm{NH}_{4}$ (uptake rate) & 0.0025 & $(\mathrm{mg} \cdot C)^{-1} \cdot \mathrm{m}^{-3} \cdot$ day $^{-1}$ \\
\hline no3_ks & Affinity for $\mathrm{NO}_{3}$ (uptake rate) & 0.0025 & $(\mathrm{mg} \cdot C)^{-1} \cdot \mathrm{m}^{-3} \cdot$ day $^{-1}$ \\
\hline
\end{tabular}

Table 5. General parameters (not necessarily related with any functional group).

\begin{tabular}{cccc}
\hline Parameter & Description & Reference Value & Units \\
\hline bio_si_diss & Biogenic silica dissolution rate & 0.01 & $\mathrm{day}^{-1}$ \\
pom_bac_ks & POM hydrolysis half saturation constant & 32 & $\mathrm{mg} \cdot C \cdot \mathrm{m}^{-3}$ \\
pom_bac_vmax & Maximum rate for POM hydrolysis & 0.5 & $\mathrm{day}^{-1}$ \\
domsl_bac_ks & DOMsl hydrolysis half saturation constant & 200 & $\mathrm{mg} \cdot C \cdot \mathrm{m}^{-3}$ \\
domsl_bac_vmax & Maximum rate for DOMsl hydrolysis & 1 & $\mathrm{day}^{-1}$ \\
nitrifradlim & Light intensity threshold for nitrification & 4 & $\mathrm{~W} \cdot \mathrm{m}^{-2}$ \\
nitrifrate & Nitrification rate & 0.04 & $\mathrm{day}^{-1}$ \\
nit_in_coef & First-order nitrification inhibition coefficient & 0.6 & $1 \mathrm{mg}^{-1}$ \\
\hline
\end{tabular}



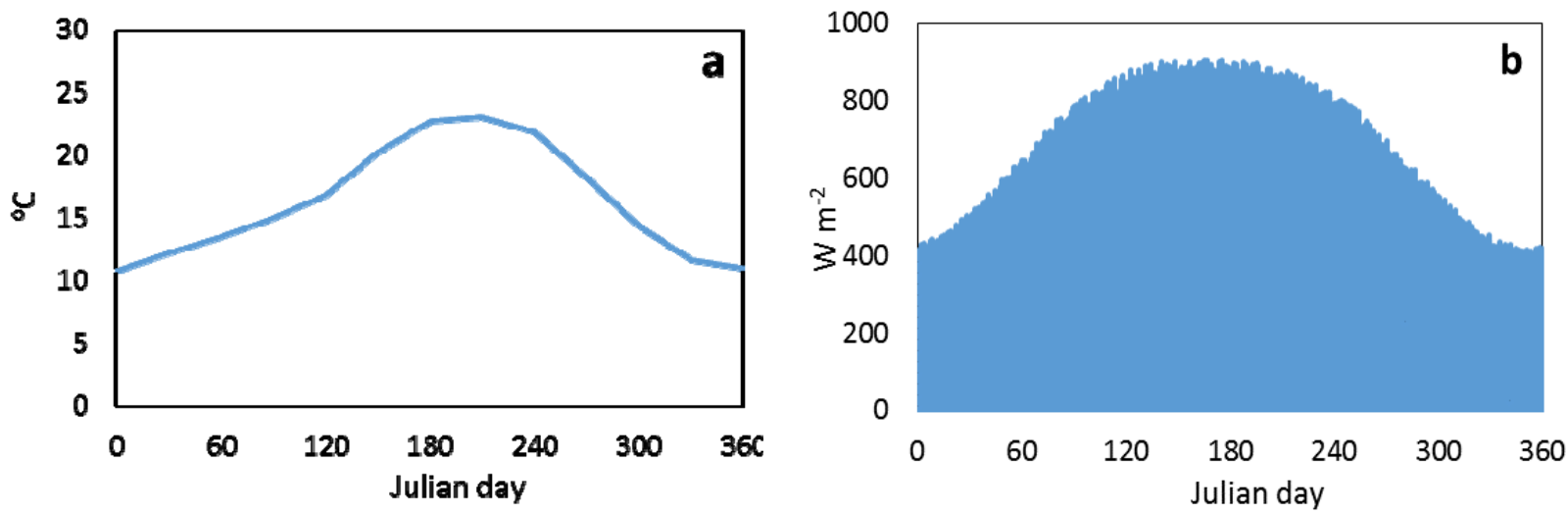

Figure 1. Environmental conditions used to force the model: (a) Surface temperature and (b) Daily maximum solar radiation.

\subsection{Interpretation of the Results}

A simple Visual Basic (VBA) macro was developed in Excel environment to process the huge amount of data produced by the model outputs for all the simulations. The macro loads the model results into a spreadsheet and then calculates the sensitivity index of the selected variables to each parameter. In the next step the matrix is interpreted to convert the quantitative index into a qualitative descriptor (the degree of model sensitivity), attributing the + and - symbols to indicate a positive or negative perturbation, respectively. The degree of sensitivity is then given by + and - for sensitive $(S>0.1),++$ or -- for highly sensitive $(S>1)$, and +++ or --- extremely sensitive $(S>10)$. Finally, to allow a better visualization of the results, a color code is used to identify the deferent degrees of sensitivity, positive or negative. No symbol or color is assigned when the model is not sensitive to a given parameter $(S<0.1)$. A step-wise description of this process is presented in Tables $6-8$.

Table 6. Representation of the processing and interpretation of the SA result, Step 1: the sensitivity index is calculated from the results of the simulations. Only a fraction of the results are shown for illustrative purposes. The description of parameters and variables can be found in Tables 1-5.

\begin{tabular}{cccccc}
\hline Ammonia & Nitrate & $\begin{array}{c}\text { Inorganic } \\
\text { Phosphorus }\end{array}$ & Silicate Acid & $\begin{array}{c}\text { Biogenic } \\
\text { Silica }\end{array}$ & Oxygen \\
\hline 2.790 & 10.600 & 0.945 & 2.850 & 3.180 & 8.560 \\
2.820 & 10.600 & 0.948 & 3.070 & 2.960 & 8.560 \\
2.790 & 10.600 & 0.941 & 3.070 & 2.960 & 8.560 \\
2.800 & 10.600 & 0.945 & 3.070 & 2.960 & 8.560 \\
2.800 & 10.600 & 0.945 & 3.070 & 2.960 & 8.560 \\
2.810 & 10.600 & 0.945 & 3.070 & 2.960 & 8.560 \\
3.080 & 10.400 & 0.945 & 3.070 & 2.960 & 8.560 \\
2.810 & 10.600 & 0.945 & 3.070 & 2.960 & 8.560 \\
\hline
\end{tabular}


Table 7. Representation of the processing and interpretation of the SA result, Step 2: the sensitivity index is arranged in a matrix that relates input parameters and output variables.

\begin{tabular}{|c|c|c|c|c|c|c|c|c|c|}
\hline \multirow{2}{*}{ Parameter } & \multirow{2}{*}{ Ref Value } & \multicolumn{2}{|c|}{ Perturbation } & \multicolumn{2}{|c|}{ Pc } & \multicolumn{2}{|c|}{$\mathrm{Zc}$} & \multicolumn{2}{|c|}{ Bc } \\
\hline & & $+10 \%$ & $+10 \%$ & $+10 \%$ & $+10 \%$ & $-10 \%$ & $+10 \%$ & $-10 \%$ & $+10 \%$ \\
\hline bio_si_diss & 0.01 & 0.009 & 0.011 & 2.892 & 2.795 & 0.097 & 0.000 & 0.000 & 0.000 \\
\hline pom_bac_ks & 32 & 28.8 & 35.2 & 5.073 & 10.032 & 0.097 & 0.097 & 0.204 & 0.204 \\
\hline pom_bac_vmax & 0.5 & 0.45 & 0.55 & -26.672 & -6.268 & -0.194 & -0.291 & -0.476 & -0.340 \\
\hline domsl_bac_ks & 200 & 180 & 220 & 0.000 & 0.000 & 0.000 & 0.000 & 0.000 & 0.000 \\
\hline domsl_bac_vmax & 1 & 0.9 & 1.1 & 0.000 & 0.000 & 0.000 & 0.000 & 0.000 & 0.000 \\
\hline nitrifradlim & 4 & 3.6 & 4.4 & 0.000 & 0.000 & 0.000 & 0.000 & 0.000 & 0.000 \\
\hline nitrifrate & 0.04 & 0.036 & 0.044 & 0.016 & 0.016 & 0.000 & 0.000 & 0.000 & 0.000 \\
\hline nit_in_coef & 0.6 & 0.54 & 0.66 & 0.000 & 0.000 & 0.000 & 0.000 & 0.000 & 0.000 \\
\hline
\end{tabular}

Table 8. Representation of the processing and interpretation of the SA result, Step 3: for a straightforward interpretation, the sensitivity value is converted to a qualitative descriptor, using signs ( + and - ) and a color scale to indicate positive or negative perturbation, and the degree of sensitivity of a variable to a given parameter.

\begin{tabular}{|c|c|c|c|c|c|c|}
\hline \multirow{2}{*}{ Parameter } & \multicolumn{2}{|c|}{ Pc } & \multicolumn{2}{|c|}{$\mathbf{Z c}$} & \multicolumn{2}{|c|}{ Bc } \\
\hline & $+10 \%$ & $+10 \%$ & $-10 \%$ & $+10 \%$ & $-10 \%$ & $+10 \%$ \\
\hline bio_si_diss & ++ & ++ & & & & \\
\hline pom_bac_ks & ++ & ++ & & & - & - \\
\hline pom_bac_vmax & --- & -- & - & - & - & - \\
\hline domsl_bac_ks & & & & & & \\
\hline domsl_bac_vmax & & & & & & \\
\hline nitrifradlim & & & & & & \\
\hline nitrifrate & & & & & & \\
\hline nit_in_coef & & & & & & \\
\hline
\end{tabular}

Notes: sensitive; $\square$ highly sensitive; $\square$ extremely sensitive.

\section{Results}

The effect of 68 parameters was tested for their positive and negative variation influence on 11 variables, resulting in a matrix of results with 1496 values. For simplicity, only the most relevant parameter influences on model results, i.e., denoting moderate or high model sensitivity toward that parameter, are discussed. The results are presented in tables for each functional group parameters and for the general parameters, where the impact of each parameter perturbation is expressed in a qualitative way. The tables provide a condensed view of the complexity of the interrelations between parameters and variables within the model.

The simulated period was chosen to have temporal variability, namely the formation and destruction of spring bloom of phytoplankton, thus avoiding a period of model stasis. Results of the reference run are illustrated in Figure 2. 


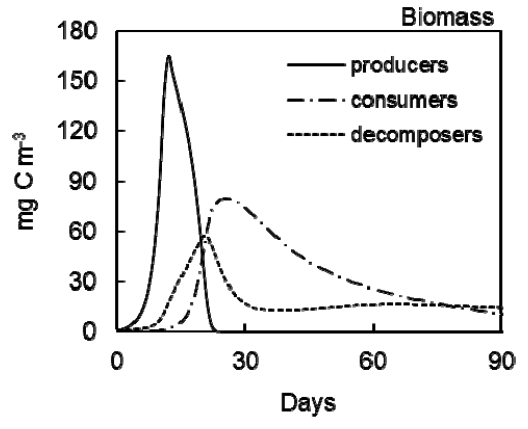

(a)

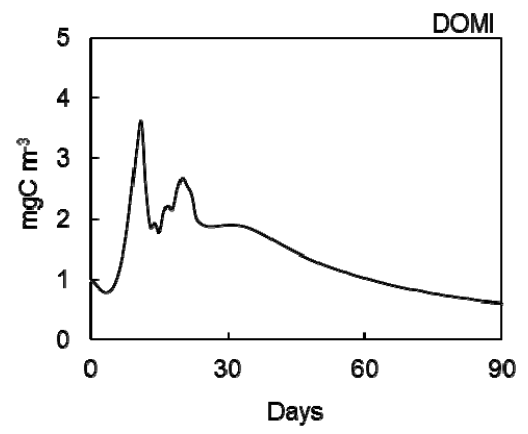

(c)

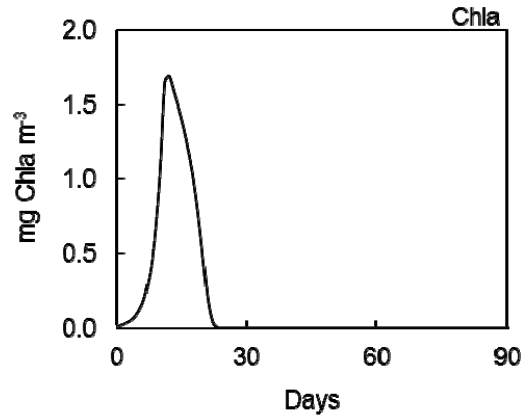

(b)

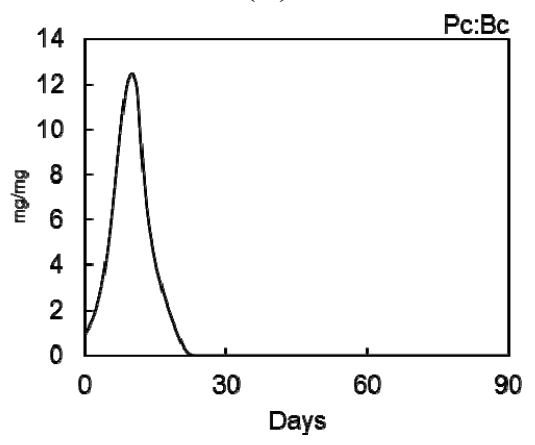

(d)

Figure 2. Results for (a) biomass of producers, consumers and decomposers; (b) chlorophyll a (Chla) concentration; (c) labile dissolved organic carbon; and (d) producers:decomposers ratio.

\subsection{General Parameters}

Variables sensitivity to general parameters is represented in Table 9, where it is possible to see that only three parameters (bio_si_diss, pom_bac_ks and pom_bac_vmax) have a significant impact on the results $(>1 \%)$. Biogenic silica dissolution rate (bio_si_diss) perturbation induces a moderate change in results, especially in producers (also reflected in chlorophyll) and consequently on the $\mathrm{P}_{\mathrm{c}}$ : $\mathrm{B}_{\mathrm{c}}$ ratio.

Pom_bac_ks and pom_bac_vmax induce small changes in nutrient variables, but have a high impact on producers (and all related variables), especially pom_bac_vmax $(S>10 \%)$. A negative perturbation of this parameter leads to the increase in the biomass of producers, and a positive perturbation has the contrary effect. This parameter controls the rate at which hydrolysis converts POM to DOM, a substrate for decomposers. This means the higher pom_bac_vmax is, more DOM is made available for decomposers; these will compete with producers for nutrients thus impacting their growth.

\subsection{Producers' Parameters}

The SA of producers' parameters (Table 10), shows a minor impact of their perturbation in the result of consumers and decomposers, the exception being for max_assimil and ref_temp with a sensitivity of $S>0.1$ in consumers. Overall, nutrient affinity to both forms of nitrogen were the parameters with less effect on any of the variables. The model is extremely sensitive $(S>10)$ only to three parameters, namely, exudation under nutrient stress (exu_nut_stress), maximum assimilation rate (max_assimil), and reference temperature (ref_temp). The effect of these parameters is particularly 
strong in all phytoplankton related variables (biomass and Chla content), a fact also observed in other studies [15]. In this particular case, the simulation ends in a situation of apparent nutrient shortage, and as nutrient limitation increases, the influence of parameters governing growth and response to nutrient stress increases. This is observed in the decrease of exu_nut_stress, meaning less exudation under nutrient stress, resulting in a positive perturbation on the biomass of producers.

The highest observed sensitivity is for the ref_temp upper perturbation in Chla. Overall, ref_temp is the parameter to which producers are more sensitive, an expected occurrence given the control of temperature on several physiological processes.

\subsection{Consumers' Parameters}

Globally, the model is more sensitive to consumers' parameters. SA results in Table 11 show that only some variables are sensitive $(S>0.1)$ to minimum and maximum nutrient:carbon ratios, and that the model is highly or extremely sensitive to all other parameter, especially the variables related to phytoplankton (biomass, Chla, $\mathrm{P}_{\mathrm{c}}: \mathrm{B}_{\mathrm{c}}$ ). Consumers parameterization is important to the control of both producers and consumers groups, and not so relevant for the decomposers and organic matter dynamics.

The highest sensitivity values observed are for assimil_effic and $p \_g r a z \_a v a i l$ by Chla and $\mathrm{P}_{\mathrm{c}}$. The sensitive index observed in Chla for assimil_effic has the highest value in the SA. Figure 3 illustrates the influence of these parameters on the temporal evolution of some variables, and it is possible to notice that, while $Z_{c}$ and $B_{c}$ are not as sensitive as $P_{c}$, their dynamics is affected by this parameter. When compared to the parameter sets of other groups, consumer parameters have the strongest effect on model behavior, most probably due to the grazing control that consumers have on producers.

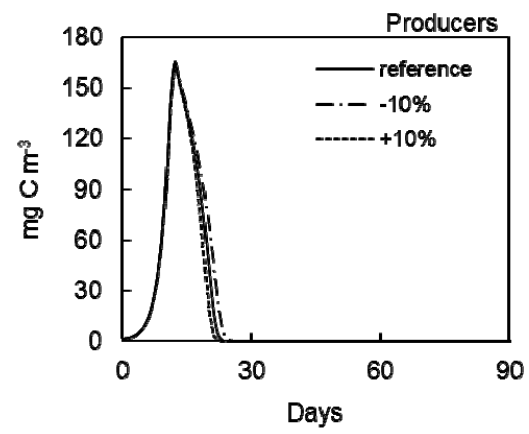

(a)

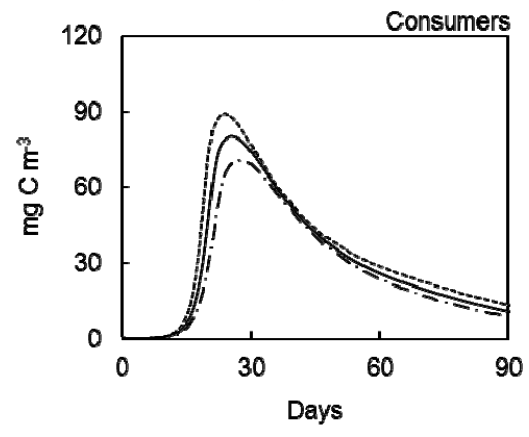

(c)

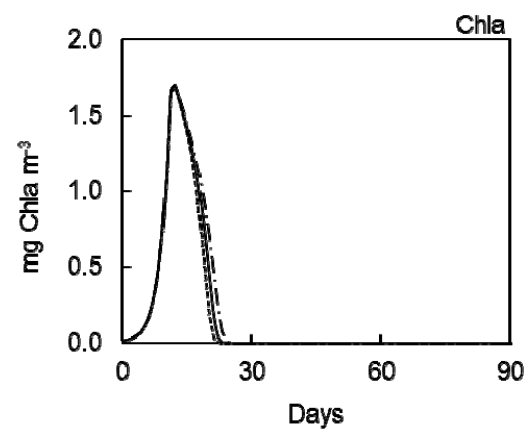

(b)

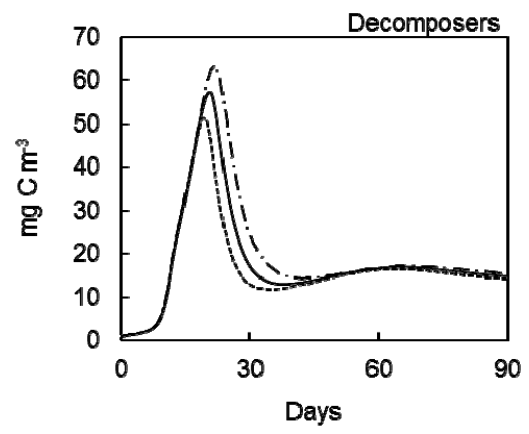

(d)

Figure 3. Temporal evolution of the response of (a) producers biomass; (b) chlorophyll $a$ (Chla); (c) consumers biomass; and (d) decomposers biomass to the perturbation of assimil_effic. 
Table 9. SA result matrix for the general parameters impact on the analyzed variables. Color code: blue for sensitive $(S>0.1)$, orange for highly sensitive $(S>1)$ and red for extremely sensitive $(\mathrm{S}>10)$. The signs + and - stand for positive and negative perturbation, respectively. A description of the variables and parameters is found in Tables $1-5$.

\begin{tabular}{|c|c|c|c|c|c|c|c|c|c|c|c|c|c|c|c|c|c|c|c|c|}
\hline \multirow{2}{*}{ Parameter } & \multicolumn{2}{|c|}{ Pc } & \multicolumn{2}{|c|}{$\mathrm{Zc}$} & \multicolumn{2}{|c|}{ Bc } & \multicolumn{2}{|c|}{ NH4 } & \multicolumn{2}{|c|}{ NO3 } & \multicolumn{2}{|c|}{ PO4 } & \multicolumn{2}{|c|}{$\mathbf{S i}$} & \multicolumn{2}{|c|}{ Chla } & \multicolumn{2}{|c|}{ DOMI } & \multicolumn{2}{|c|}{ Pc:Bc } \\
\hline & $-10 \%$ & $+10 \%$ & $-10 \%$ & $+10 \%$ & $-10 \%$ & $+10 \%$ & $-10 \%$ & $+10 \%$ & $-10 \%$ & $+10 \%$ & $-10 \%$ & $+10 \%$ & $-10 \%$ & $+10 \%$ & $-10 \%$ & $+10 \%$ & $-10 \%$ & $+10 \%$ & $-10 \%$ & $+10 \%$ \\
\hline bio_si_diss & ++ & ++ & & & & & & & & & & & - & - & ++ & ++ & + & & ++ & ++ \\
\hline pom_bac_ks & ++ & ++ & & & - & - & & & & & & & & & ++ & ++ & - & & ++ & ++ \\
\hline pom_bac_vmax & --- & -- & - & - & - & - & & & & & & & & & --- & -- & - & - & --- & -- \\
\hline domsl_bac_ks & & & & & & & & & & & & & & & & & & & & \\
\hline nitrifradlim & & & & & & & & & & & & & & & & & & & & \\
\hline nitrifrate & & & & & & & - & - & - & - & & & & & & & & & & \\
\hline nit_in_coef & & & & & & & & & & & & & & & & & & & & \\
\hline
\end{tabular}

Table 10. SA result matrix for producers' parameters impact on the analyzed variables. Color code: blue for sensitive $(S>0.1)$, orange for highly sensitive $(S>1)$ and red for extremely sensitive $(S>10)$. The signs + and - stand for positive and negative perturbation, respectively. A description of the variables and parameters is found in Tables 1 and 2, respectively.

\begin{tabular}{|c|c|c|c|c|c|c|c|c|c|c|c|c|c|c|c|c|c|c|c|c|}
\hline \multirow{2}{*}{ Parameter } & \multicolumn{2}{|c|}{ Pc } & \multicolumn{2}{|c|}{$\mathrm{Zc}$} & \multicolumn{2}{|c|}{ Bc } & \multicolumn{2}{|c|}{ NH4 } & \multicolumn{2}{|c|}{$\mathrm{NO3}$} & \multicolumn{2}{|c|}{ PO4 } & \multicolumn{2}{|c|}{$\mathbf{S i}$} & \multicolumn{2}{|c|}{ Chla } & \multicolumn{2}{|c|}{ DOMI } & \multicolumn{2}{|c|}{ Pc:Bc } \\
\hline & $-10 \%$ & $+10 \%$ & $-10 \%$ & $+10 \%$ & $-10 \%$ & $+10 \%$ & $-10 \%$ & $+10 \%$ & $-10 \%$ & $+10 \%$ & $-10 \%$ & $+10 \%$ & $-10 \%$ & $+10 \%$ & $-10 \%$ & $+10 \%$ & $-10 \%$ & $+10 \%$ & $-10 \%$ & $+10 \%$ \\
\hline min_nc_ratio & - & & & & & & & & & & & & & & - & & & - & - & \\
\hline max_nc_ratio & ++ & ++ & & & & & - & - & - & & & & & & ++ & ++ & + & - & ++ & ++ \\
\hline min_pc_ratio & - & & & & & & & & & & & & & & - & & & & - & \\
\hline max_pc_ratio & & + & & & & & & & & & & & & & & + & + & & & + \\
\hline max_chln_ratio & ++ & ++ & & & & & & & & & & & & & ++ & ++ & & - & ++ & ++ \\
\hline chl_degrad_rate & & & & & & & & & & & & & & & & & & & & \\
\hline alpha_chl & ++ & ++ & & & & & & & & & & & & & ++ & ++ & & - & ++ & ++ \\
\hline affinity_nh4 & & & & & & & & & & & & & & & - & & + & & & \\
\hline
\end{tabular}


Table 10. Cont.

\begin{tabular}{|c|c|c|c|c|c|c|c|c|c|c|c|c|c|c|c|c|c|c|c|c|}
\hline \multirow[t]{2}{*}{ Parameter } & \multicolumn{2}{|c|}{ Pc } & \multicolumn{2}{|c|}{$\mathrm{Zc}$} & \multicolumn{2}{|c|}{ Bc } & \multicolumn{2}{|c|}{ NH4 } & \multicolumn{2}{|c|}{ NO3 } & \multicolumn{2}{|c|}{ PO4 } & \multicolumn{2}{|c|}{ Si } & \multicolumn{2}{|c|}{ Chla } & \multicolumn{2}{|c|}{ DOMI } & \multicolumn{2}{|c|}{ Pc:Bc } \\
\hline & $-10 \%$ & $+10 \%$ & $-10 \%$ & $+10 \%$ & $-10 \%$ & $+10 \%$ & $-10 \%$ & $+10 \%$ & $-10 \%$ & $+10 \%$ & $-10 \%$ & $+10 \%$ & $-10 \%$ & $+10 \%$ & $-10 \%$ & $+10 \%$ & $-10 \%$ & $+10 \%$ & $-10 \%$ & $+10 \%$ \\
\hline affinity_no3 & - & & & & & & & - & & & & & & & - & & & & - & \\
\hline \multicolumn{21}{|l|}{ affinity_po4 } \\
\hline exu_nut_stress & --- & -- & & & & & & & & & & & & & --- & -- & + & & -- & -- \\
\hline exc_dom_sl_frac & - & - & & & & & & & & & & & & & - & - & & & - & - \\
\hline max_assimil & ++ & +++ & - & - & & & & & & & & & & & ++ & +++ & & - & ++ & +++ \\
\hline max_store_fill & & & & & & & & & & & & & & & & & - & & & \\
\hline min_lysis & -- & -- & & & & & & & & & & & & & -- & -- & + & & -- & -- \\
\hline mort_dom_sl_frac & - & - & & & & & & & & & & & & & - & - & & & - & - \\
\hline ref_temp & --- & -- & - & - & & & & - & & & & & & & --- & -- & + & & --- & -- \\
\hline rel_excess_si & -- & & & & & & & & & & & & & & -- & & & & -- & \\
\hline resp_basal & -- & -- & & & & & & & & & & & & & -- & -- & + & & -- & -- \\
\hline resp_frac_prod & -- & -- & & & & & & & & & & & & & -- & -- & + & & -- & -- \\
\hline sedim_min & & & & & & & & & & & & & & & & & & & & \\
\hline sedim_nut_stress & & & & & & & & - & & & & & & & & & & & & \\
\hline si_uptake_ks & -- & -- & & & & & & & & & & & & & -- & -- & + & & -- & -- \\
\hline nut_stress_thresh & & & & & & & & & & & & & & & & & & & & \\
\hline
\end{tabular}


Table 11. SA result matrix for consumers' parameters impact on the analyzed variables. Color code: blue for sensitive $(S>0.1)$, orange for highly sensitive $(S>1)$ and red for extremely sensitive $(S>10)$. The signs + and - stand for positive and negative perturbation, respectively. A description of the variables and parameters is found in Tables 1 and 3 , respectively.

\begin{tabular}{|c|c|c|c|c|c|c|c|c|c|c|c|c|c|c|c|c|c|c|c|c|}
\hline \multirow{2}{*}{ Parameter } & \multicolumn{2}{|c|}{$\mathbf{P c}$} & \multicolumn{2}{|c|}{$\mathrm{Zc}$} & \multicolumn{2}{|c|}{$\mathbf{B c}$} & \multicolumn{2}{|c|}{ NH4 } & \multicolumn{2}{|c|}{$\mathrm{NO3}$} & \multicolumn{2}{|c|}{ PO4 } & \multicolumn{2}{|c|}{ Si } & \multicolumn{2}{|c|}{ Chla } & \multicolumn{2}{|c|}{ DOMI } & \multicolumn{2}{|c|}{ Pc:Bc } \\
\hline & $-10 \%$ & $+10 \%$ & $-10 \%$ & $+10 \%$ & $-10 \%$ & $+10 \%$ & $-10 \%$ & $+10 \%$ & $-10 \%$ & $+10 \%$ & $-10 \%$ & $+10 \%$ & $-10 \%$ & $+10 \%$ & $-10 \%$ & $+10 \%$ & $-10 \%$ & $+10 \%$ & $-10 \%$ & $+10 \%$ \\
\hline max_nc_ratio & & & & & & & - & & & & & & & & & & + & & & \\
\hline max_pc_ratio & - & & & & & & & & & & - & & & & - & & - & & - & \\
\hline min_nc_ratio & & & & & & & - & - & & & & & & & & & & & & \\
\hline min_pc_ratio & & + & & & & & & & & & & - & & & & + & & + & & + \\
\hline excre_up_frac &.- & -- & + & ++ & + & + & & - & & & & & & & -- & -- & + & + & - & -- \\
\hline mort_o2_dep & ++ & ++ & & & + & & & - & & & & & & & ++ & ++ & & & ++ & ++ \\
\hline mort_pom_frac & ++ & ++ & + & + & + & + & & & & & & & & & ++ & ++ & + & 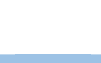 & ++ & ++ \\
\hline mort_rate & ++ & +++ & & & + & + & & & & & & & & & ++ & +++ & - & - & ++ & +++ \\
\hline o2_ks & ++ & ++ & & & + & & & & & & & & & & ++ & ++ & & - & ++ & ++ \\
\hline ref_temp & ++ & +++ & ++ & ++ & + & + & + & + & & & & & - & - & ++ & +++ & + & + & ++ & +++ \\
\hline rest_resp_@10c & ++ & +++ & -- & -- & + & & & & & & & & & & ++ & +++ & - & - & ++ & +++ \\
\hline assimil_effic & - & -- & ++ & ++ & + & + & - & & & & & & - & - & -- & -- & + & + & -- & -- \\
\hline max_spec_up_@10c & - & -- & & 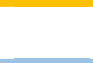 & - & - & - & - & & & & & - & - & $\ldots$ & -- & & & --- & -- \\
\hline graz_up_ks & ++ & +++ & - & - & + & + & & + & & & & & & & ++ & +++ & - & - & ++ & +++ \\
\hline p_graz_avail & -- & -- & - & - & 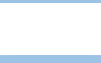 & 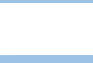 & - & - & & & & & & & --- & -- & & - & -- & -- \\
\hline d_graz_avail & -- & -- & + & + & - & - & & & & & & & & & -- & -- & + & + & -- & - \\
\hline
\end{tabular}


Table 12. SA result matrix for decomposers parameters impact on the analyzed variables. Color code: blue for sensitive $(S>0.1)$, orange for highly sensitive $(S>1)$ and red for extremely sensitive $(S>10)$. The signs + and - stand for positive and negative perturbation, respectively. A description of the variables and parameters is found in Tables 1 and 4 , respectively.

\begin{tabular}{|c|c|c|c|c|c|c|c|c|c|c|c|c|c|c|c|c|c|c|c|c|}
\hline \multirow{2}{*}{ Parameter } & \multicolumn{2}{|c|}{ Pc } & \multicolumn{2}{|c|}{$\mathrm{Zc}$} & \multicolumn{2}{|c|}{ Bc } & \multicolumn{2}{|c|}{ NH4 } & \multicolumn{2}{|c|}{ NO3 } & \multicolumn{2}{|c|}{ PO4 } & \multicolumn{2}{|c|}{$\mathbf{S i}$} & \multicolumn{2}{|c|}{ Chla } & \multicolumn{2}{|c|}{ DOMI } & \multicolumn{2}{|c|}{ Pc:Bc } \\
\hline & $-10 \%$ & $+10 \%$ & $-10 \%$ & $+10 \%$ & $-10 \%$ & $+10 \%$ & $-10 \%$ & $+10 \%$ & $-10 \%$ & $+10 \%$ & $-10 \%$ & $+10 \%$ & $-10 \%$ & $+10 \%$ & $-10 \%$ & $+10 \%$ & $-10 \%$ & $+10 \%$ & $-10 \%$ & $+10 \%$ \\
\hline min_nc_ratio & & - & & & & & + & + & & & & & & & & - & & - & & - \\
\hline max_nc_ratio & + & & & & & & - & + & & & & & & & + & & & & + & \\
\hline min_pc_ratio & & & & & & & & & & & & & & & & & + & & & \\
\hline max_pc_ratio & & & & & & & & & & & & & & & & & & - & & \\
\hline ass_effic & & & & & & & & & & & & & & & & & + & & & \\
\hline ass_effic_low_02 & & & & & & & & & & & & & & & & & & & & \\
\hline dens_dep_mort & ++ & ++ & & & & & & & & & & & & & ++ & ++ & + & + & ++ & ++ \\
\hline lys_ref_con & -- & -- & & & & & & & & & & & & & -- & -- & - & - & -- & -- \\
\hline max_spec_up_@10c & - & - & & & & & & & & & & & & & - & - & -- & -- & - & - \\
\hline dom_up_ks & + & + & & & & & & & & & & & & & + & + & ++ & + & ++ & ++ \\
\hline mort_dom_sl_frac & ++ & ++ & & & & & & & & & & & & & ++ & ++ & & & ++ & -- \\
\hline mort_pom_frac & ++ & + & & & & & & & & & & & & & ++ & + & & & ++ & + \\
\hline mort_rate & ++ & & & & + & + & & & & & & & & & ++ & ++ & + & + & ++ & ++ \\
\hline o2_ks & + & + & & & & & & & & & & & & & + & + & + & - & + & + \\
\hline o2_low_ass_efic & & & & & & & & & & & & & & & & & & & & \\
\hline rest_resp_@10c & ++ & ++ & & - & & & & & & & & & & & ++ & ++ & & - & ++ & ++ \\
\hline ref_temp & ++ & +++ & + & + & + & + & & & & & & & & & ++ & +++ & & ++ & ++ & +++ \\
\hline po4_ks & & & & & & & & & & & & & & & & & & & & \\
\hline nh4_ks & & & & & & & & & & & & & & & & & + & & & \\
\hline no3_ks & & & & & & & & & & & & & & & & & & & & \\
\hline
\end{tabular}




\subsection{Decomposers' Parameters}

The results for the SA analysis on decomposers parameters are illustrated in Table 12. The model only shows to be extremely sensitive $(S>10)$ to the positive perturbation of ref_temp, and the effect of the perturbation in the outcome of the model can be seen in Figure 4. Despite the oscillation seen in the time series, the simulations converge to a similar result. As in producers, the strong control of temperature on physiologic functions makes the model extremely sensitivity to temperature reference values.

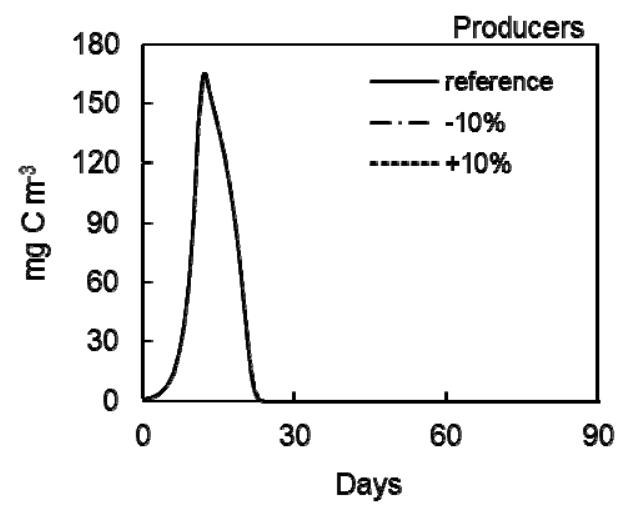

(a)

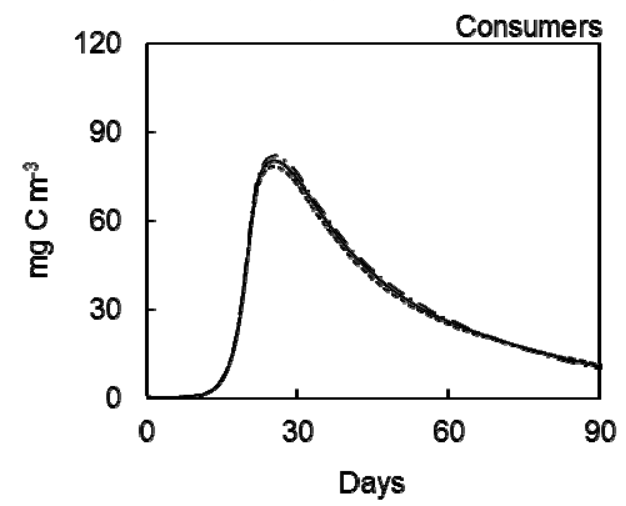

(c)

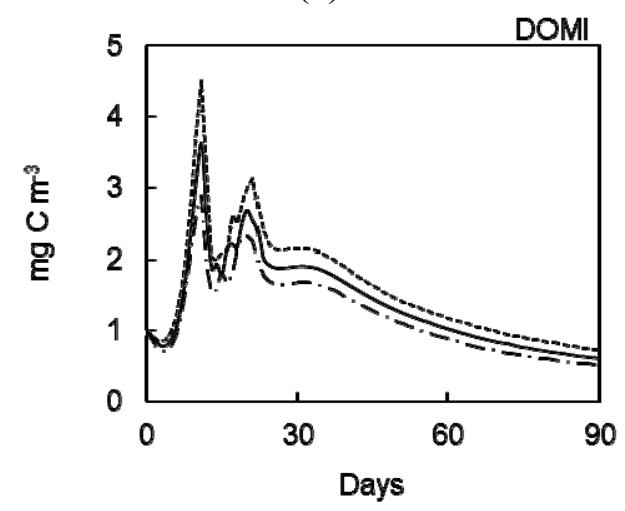

(e)

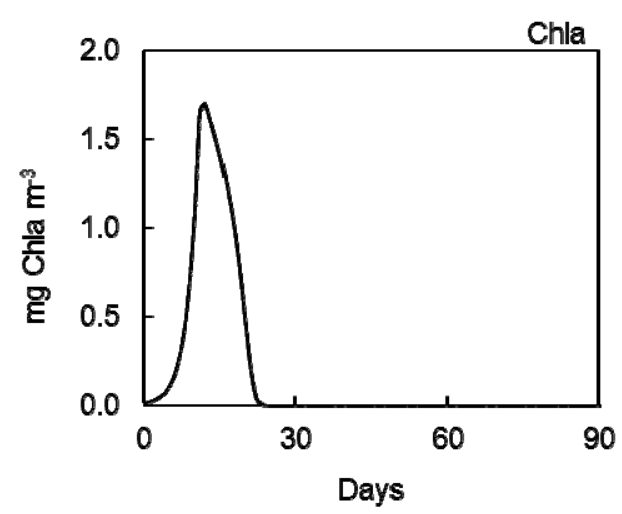

(b)

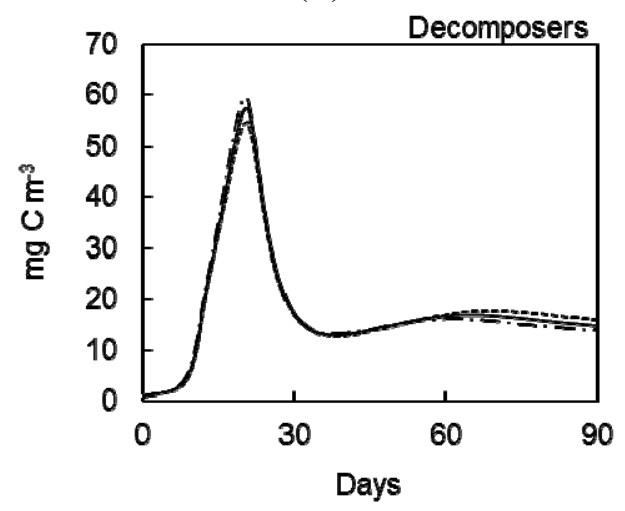

(d)

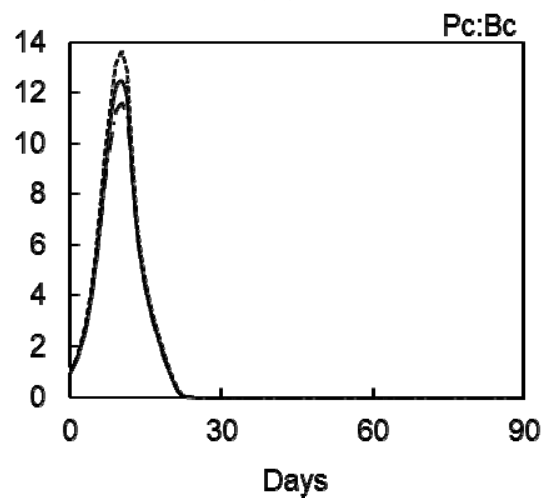

(f)

Figure 4. Temporal evolution of the response of (a) producers biomass, (b) chlorophyll $a$ (Chla), (c) consumers biomass, (d) decomposers biomass, (e) labile dissolved organic carbon, and (f) producers:decomposers ratio to the perturbation of ref_temp (decomposers). 
Producers and related variables are the most sensitive to decomposers parameter perturbation. This is an expected outcome, since the microbial loop control much of the available nutrients (via respiration of organic matter), affecting directly the dynamics of nutrient uptake by producers. This effect, however, is not noticed in the nutrient variables, meaning that they are being consumed as they become available. DOMl also shows sensitivity to the perturbation of the parameters that control its mineralization by bacteria, as seen in Figure 4. The affinity for nutrient does not show any relevant disturbance on model response, in a similar way as observed for producers.

\section{Discussion}

Generally, the model seems to be sensitive to most parameters. The observed sensitivity, however, is not detected in all model compartments, implying that a single parameter may have an impact on one or several state-variables, but not on the overall outcome of the model. Similar observations have been reported in similar studies $[3,4,25,28]$, and can be explained by the complexity of the model in which all state-variables are dependent on processes controlled by multiple parameters.

The model is extremely sensitive to only three parameters in producers: Exudation under nutrient stress (nut_stress_thresh), maximum assimilation rate (max_assimil), and reference temperature. Overall, reference temperature (ref_temp) is the parameter to which producers are more sensitive, an expected occurrence given the control of temperature on several physiological processes [28,29]. Results show that consumer's parameterization is particularly relevant to the control of producers, and not so important for decomposers. This is observed in the number of parameters in consumers for which $\mathrm{P}_{c}$ and Chla show high or extremely high sensitivity (Table 11). These state-variables are particularly sensitive to parameters related with the feeding and assimilation in consumers (assimil_effic, max_spec_up_@10c,graz_up_ks and p_graz_avail).

Consumers' parameters have the strongest effect on the behavior of the model, probably through grazing control on producers. Some studies have shown a similar control of consumers (zooplankton) parameters on model performance [2,15,30,31], denoting the importance of this group in ecological models for pelagic systems. Decomposers have the lowest number of parameters for which variables are extremely sensitive. This is only observed for the reference temperature (ref_temp) for this functional group (Figure 4).

Of all variables studied in this SA, nutrients were the least affected in the number of parameters to which they are sensitive. Nutrients sensitivity to parameter perturbation never exceeded $10 \%$ in the final result. From this, it is possible to conclude that nutrient variables are the most robust. It can be hypothesized, however, that model sensitivity to parameters related with nutrient dynamics may increase under nutrient limitation.

Silica is the variable affected by the lower number of different parameters, because it is the only variable depending only on producers. Remarkably, no producer parameter disruption causes any significant change in the final outcome of silica. Biogenic silica dissolution rate (bio_si_diss) perturbation produced a minor impact $(<10 \%)$ on silica, implying that the model is not very sensitive to it. Nevertheless, this parameter showed to be highly sensitive to other state-variables, namely $\mathrm{P}_{\mathrm{c}}$ and Chla. This impact is probably due to limitation by silica in producers. Small variations in these parameters will affect the amount of dissolved silica to diatoms, because it mediates the conversion of 
biogenic silica to dissolved silica. Also, the other parameters to which the model silica compartment is sensitive are related to consumers grazing activity (ref_temp, assimil_effic and max_spec_up_@10c). The grazing pressure influences silica abundance, because this element is not assimilated by consumers, but instead diverted to the biogenic silica pool.

Phosphate only reflects the variation of two parameters, the upper perturbation of max_pc_ratio and the lower perturbation of min_nc_ratio (Table 11), because they disturb the immobilization and mineralization of phosphorus. Hence, their perturbation has a direct impact on phosphate, even though not a significant impact $(<10 \%)$. Nitrate is not a product of mineralization, so it is not affected by any consumers or decomposer parameters, and is only affected by the nitrification rate perturbation (both positive and negative) and by max_nc_ratio. Of all groups, consumers have more parameters affecting ammonium dynamics, probably because of its important role in nutrient mineralization through grazing and subsequent nutrient recycling. Most of the parameters related to grazing activity have an effect on ammonium.

Ultimately, one of the main outcomes of SA is to identify where a relatively minor change in a factor's value leads to a major change in model output $[32,33]$. This is an essential procedure in conventional model development, illustrated by the volume of published works on the topic and stressed in official guidelines regarding the modeling of environmental systems (see [34,35]). In our study we opted for a local SA, where only one parameter varies at a time, while all the others remain fixed at predetermined values, instead of a global analysis in which all parameters vary [7,36]. In global SA, or total SA (sensu [37]), all factors are changed together across the full multidimensional input space. This means that the main effect of parameters and the interactions terms involving them are both included, enabling to determine if parameter influence is mostly due to interactions terms rather than to linear effects. Several studies on complex ecosystem models have shown that global SA are more useful because they address parameter interactions and potential nonlinear relationships between parameters and model outputs [12,38-41].

With the simple parameter perturbation approach used in this study it is only possible to suppose potential interactions between parameters controlling model behavior. Taking the most sensitive parameter in consumers as an example, ref_temp and max_spec_up_@10c, it is possible to infer a potential interaction in the control of consumers, producers and nutrients, because both parameters are used to determine the grazing rate. The same could be inferred for two of the most sensitive parameters in producers, ref_temp and max_assimil, since both mediate the maximum rate of photosynthesis [20].

Global SA may provide useful information on the most uncertain parameters, and it certainly shows that model parameterization should be done with carefully determined empirical values because of the interaction effects [29]. Nonetheless, a drawback in this approach relies on the extensive computation needed to address all interaction terms and total effects for each input parameter [41,42]. Because global SA aims to characterize models performance and uncertainty [42], it may represent an excessive effort when the aim is to identify key parameters to address in the calibration of the model. Similarly, it may not be as effective as local SA on illustrating the direct relationship between the perturbations of a single parameter and model output, given the volume of results produced. While not providing information on nonlinear responses and parameter interaction (or their combined effect), local SA still provides fundamental information to identify the most sensitive parameters governing model behavior. 
This is significant information because the factors the model is most sensitive to usually have stronger main rather than interaction effects [29].

Graphical representation of SA results, especially global SA, has become a challenge of its own given the continuously increase in complexity of ecological models. A way to reduce the volume of results, and to achieve simplification, relies on grouping parameters and assessing model sensitivity to these assemblages [12,43-45]. While these representations have its own benefits, they also have the obvious disadvantage of covering-up the impact of single parameters. This is, in fact, one of the aims of this methodology [46-49]. Since the objective of the work presented here was to identify the key parameters controlling the model behavior, it relied on an approach that explicitly addresses the impact of single parameters. This is a standard and essential practice in process-oriented water-quality and ecological models, because it precedes the calibration exercise $[4,5,50-55]$. Despite the argumentation on the constraints of the one-factor-at-a-time SA $[4,6,7,28]$, we have simplified the complexity in the interpretation of results by using a color-code matrix, thus minimizing some of its drawbacks. With this approaches it becomes easier to relate parameters (model input) and state-variables (model output) and have instantaneous perception on the magnitude of this relationship. When limited data sets are available (for a few state-variables, for instance), the color-code tables may well be an efficient way to calibrate a model adjusting only a few parameters.

\section{Conclusions}

Most parameters exert some influence on the selected outputs of the model, but the study shows that the proposed degree of variation in the standard parameterization does not yield a much different scenario, or leads to any significant change in the model results. In the proposed methodology, the result tables provide a condensed view on the sensitivity of state-variables to individual parameters. These tables simplify the interpretation of SA methods that produce significant amounts of results, and can be used as look-up tables to identify sensitive responses in real cases applications.

The methodology presented here is based on local SA. While not providing the same volume of information on the model behavior as a global SA, it yields fundamental information to identify the most sensitive parameters governing model behavior. As such, our approach proved to be a simple and objective way to assist in the calibration exercise of complex models.

\section{Acknowledgments}

The authors would like to thank the reviewers for providing valuable comments that helped us to improve the manuscript.

\section{Author Contributions}

Marcos D. Mateus performed the computer simulations and sensitivity tests; Guilherme Franz performed further analysis and has interpreted the results. Both authors developed the color-code matrix and worked equally on the preparation of the manuscript.

\section{Conflicts of Interest}


The authors declare no conflict of interest.

\section{References}

1. Gan, Y.J.; Duan, Q.Y.; Gong, W.; Tong, C.; Sun, Y.W.; Chu, W.; Ye, A.Z.; Miao, C.Y.; Di, Z.H. A comprehensive evaluation of various sensitivity analysis methods: A case study with a hydrological model. Environ. Modell. Softw. 2014, 51, 269-285.

2. Yoshie, N.; Yamanaka, Y.; Rose, K.A.; Eslinger, D.L.; Ware, D.M.; Kishi, M.J. Parameter sensitivity study of the nemuro lower trophic level marine ecosystem model. Ecol. Model. 2007, 202, 26-37.

3. Klepper, O. Multivariate aspects of model uncertainty analysis: Tools for sensitivity analysis and calibration. Ecol. Model. 1997, 101, 1-13.

4. Arhonditsis, G.B.; Brett, M.T. Eutrophication model for Lake Washington (USA): Part I. Model description and sensitivity analysis. Ecol. Model. 2005, 187, 140-178.

5. Wade, A.J.; Hornberger, G.M.; Whitehead, P.G.; Jarvie, H.P.; Flynn, N. On modeling the mechanisms that control in-stream phosphorus, macrophyte, and epiphyte dynamics: An assessment of a new model using general sensitivity analysis. Water Resour. Res. 2001, 37, 2777-2792.

6. Saltelli, A.; Annoni, P. How to avoid a perfunctory sensitivity analysis. Environ. Modell. Softw. 2010, 25, 1508-1517.

7. Cariboni, J.; Gatelli, D.; Liska, R.; Saltelli, A. The role of sensitivity analysis in ecological modelling. Ecol. Modell. 2007, 203, 167-182.

8. Campolongo, F.; Cariboni, J.; Saltelli, A. An effective screening design for sensitivity analysis of large models. Environ. Model. Softw. 2007, 22, 1509-1518.

9. Ratto, M.; Tarantola, S.; Saltelli, A. Sensitivity analysis in model calibration: Gsa-glue approach. Comput. Phys. Commun. 2001, 136, 212-224.

10. Borgonovo, E.; Castaings, W.; Tarantola, S. Model emulation and moment-independent sensitivity analysis: An application to environmental modelling. Environ. Model. Softw. 2012, 34, $105-115$.

11. Van Griensven, A.; Meixner, T.; Grunwald, S.; Bishop, T.; Diluzio, A.; Srinivasan, R. A global sensitivity analysis tool for the parameters of multi-variable catchment models. J. Hydrol. 2006, 324, 10-23.

12. Harper, E.B.; Stella, J.C.; Fremier, A.K. Global sensitivity analysis for complex ecological models: A case study of riparian cottonwood population dynamics. Ecol. Appl. 2011, 21, 1225-1240.

13. Rigosi, A.; Marce, R.; Escot, C.; Rueda, F.J. A calibration strategy for dynamic succession models including several phytoplankton groups. Environ. Model. Softw. 2011, 26, 697-710.

14. Ratto, M.; Castelletti, A.; Pagano, A. Emulation techniques for the reduction and sensitivity analysis of complex environmental models. Environ. Model. Softw. 2012, 34, 1-4.

15. Rodrigues, M.; Oliveira, A.; Costa, M.; Fortunato, A.B.; Zhang, Y. Sensitivity analysis of an ecological model applied to the ria de aveiro. J. Coast. Res. 2009, 56, 448-452.

16. Makler-Pick, V.; Gal, G.; Gorfine, M.; Hipsey, M.R.; Carmel, Y. Sensitivity analysis for complex ecological models-A new approach. Environ. Modell. Softw. 2011, 26, 124-134. 
17. Kohler, P.; Wirtz, K.W. Linear understanding of a huge aquatic ecosystem model using a group-collecting sensitivity analysis. Environ. Modell. Softw. 2002, 17, 613-625.

18. Bayarri, M.J.; Berger, J.; Steinberg, D.M. Special issue on computer modeling. Technometrics 2009, 51, 353-353.

19. Oakley, J.E.; O'Hagan, A. Probabilistic sensitivity analysis of complex models: A bayesian approach. J. R. Stat. Soc. B 2004, 66, 751-769.

20. Mateus, M. A process-oriented model of pelagic biogeochemistry for marine systems. Part I: Model description. J. Marine Syst. 2012, 94, S78-S89.

21. Mateus, M.; Leitão, P.C.; de Pablo, H.; Neves, R. Is it relevant to explicitly parameterize chlorophyll synthesis in marine ecological models? J. Marine Syst. 2012, 94, S23-S33.

22. Cochrane, K.L.; James, A.G.; Mitchellinnes, B.A.; Pitcher, G.C.; Verheye, H.M.; Walker, D.R. Short-term variability during an anchor station study in the southern benguela upwelling system-A simulation-model. Prog. Oceanogr. 1991, 28, 121-152.

23. Anderson, T.R. Modeling the influence of food $\mathrm{cn}$ ratio, and respiration on growth and nitrogen-excretion in marine zooplankton and bacteria. J. Plankton Res. 1992, 14, 1645-1671.

24. Risbey, J.; van der Sluijs, J.; Kloprogge, P.; Ravetz, J.; Funtowicz, S.; Quintana, S.C. Application of a checklist for quality assistance in environmental modelling to an energy model. Environ. Model. Assess. 2005, 10, 63-79.

25. Estrada, V.; Diaz, M.S. Global sensitivity analysis in the development of first principle-based eutrophication models. Environ. Model. Softw. 2010, 25, 1539-1551.

26. Fasham, M.J.R.; Ducklow, H.W.; Mckelvie, S.M. A nitrogen-based model of plankton dynamics in the oceanic mixed layer. J. Marine Res. 1990, 48, 591-639.

27. Blumberg, A.F.; Georgas, N. Quantifying uncertainty in estuarine and coastal ocean circulation modeling. J. Hydraul. Eng. 2008, 134, 403-415.

28. Morris, D.J.; Speirs, D.C.; Cameron, A.I.; Heath, M.R. Global sensitivity analysis of an end-to-end marine ecosystem model of the north sea: Factors affecting the biomass of fish and benthos. Ecol. Model. 2014, 279, 114-117.

29. Wang, F.; Mladenoff, D.J.; Forrester, J.A.; Keough, C.; Parton, W.J. Global sensitivity analysis of a modified century model for simulating impacts of harvesting fine woody biomass for bioenergy. Ecol. Model. 2013, 259, 16-23.

30. Steele, J.H.; Henderson, E.W. A simple-model for plankton patchiness. J. Plankton Res. 1992, 14, 1397-1403.

31. Steele, J.H.; Henderson, E.W. The role of predation in plankton models. J. Plankton Res. 1992, 14, 157-172.

32. Link, J.S.; Ihde, T.F.; Harvey, C.J.; Gaichas, S.K.; Field, J.C.; Brodziak, J.K.T.; Townsend, H.M.; Peterman, R.M. Dealing with uncertainty in ecosystem models: The paradox of use for living marine resource management. Prog. Oceanogr. 2012, 102, 102-114.

33. Arhonditsis, G.B.; Brett, M.T. Evaluation of the current state of mechanistic aquatic biogeochemical modeling. Mar. Ecol. Prog. Ser. 2004, 271, 13-26.

34. European Commission. Impact Assessment Guidelines sec(2009)92. Available online: $\mathrm{http} / / /$ ec.europa.eu/smart-regulation/impact/commission_guidelines/docs/iag_2009_en.pdf (accessed on 23 April 2015). 
35. U.S. Environmental Protection Agency. Guidance on the Development, Evaluation and Application of Regulatory Environmental Models; Office of the Federal Register, National Archives and Records Administration : Washington, DC, USA, 2009.

36. Saltelli, A.; Ratto, M.; Andres, T.; Campolongo, F.; Cariboni, J.; Gatelli, D.; Saisana, M.; Tarantola, S. Global Sensitivity Analysis: The Primer; Wiley-Interscience: Chichester, West Sussex, UK, 2008.

37. Saltelli, A.; Tarantola, S.; Chan, K.P.S. A quantitative model-independent method for global sensitivity analysis of model output. Technometrics 1999, 41, 39-56.

38. Chu-Agor, M.L.; Muñoz-Carpena, R.; Kiker, G.; Emanuelsson, A.; Linkov, I. Exploring vulnerability of coastal habitats to sea level rise through global sensitivity and uncertainty analyses. Environ. Model. Softw. 2011, 26, 593-604.

39. Miao, Z.; Lathrop, R.G., Jr.; Xu, M.; la Puma, I.P.; Clark, K.L.; Hom, J.; Skowronski, N.; van Tuyl, S. Simulation and sensitivity analysis of carbon storage and fluxes in the New Jersey pinelands. Environ. Model. Softw. 2011, 26, 1112-1122.

40. Zador, J.; Zsely, I.G.; Turanyi, T. Local and global uncertainty analysis of complex chemical kinetic systems. Reliab. Eng. Syst. Saf. 2006, 91, 1232-1240.

41. Francos, A.; Elorza, F.J.; Bouraoui, F.; Bidoglio, G.; Galbiati, L. Sensitivity analysis of distributed environmental simulation models: Understanding the model behaviour in hydrological studies at the catchment scale. Reliab. Eng. Syst. Saf. 2003, 79, 205-218.

42. Bennett, N.D.; Croke, B.F.W.; Guariso, G.; Guillaume, J.H.A.; Hamilton, S.H.; Jakeman, A.J.; Marsili-Libelli, S.; Newham, L.T.H.; Norton, J.P.; Perrin, C.; et al. Characterising performance of environmental models. Environ. Model. Softw. 2013, 40, 1-20.

43. Knights, A.M.; Piet, G.J.; Jongbloed, R.H.; Tamis, J.E.; White, L.; Akoglu, E.; Boicenco, L.; Churilova, T.; Kryvenko, O.; Fleming-Lehtinen, V.; et al. An exposure-effect approach for evaluating ecosystem-wide risks from human activities. ICES J. Marine Sci. 2015, 72, 1105-1115.

44. Alvarez, M.C.; Franco, A.; Perez-Dominguez, R.; Elliott, M. Sensitivity analysis to explore responsiveness and dynamic range of multi-metric fish-based indices for assessing the ecological status of estuaries and lagoons. Hydrobiologia 2013, 704, 347-362.

45. Brun, R.; Reichert, P.; Kunsch, H.R. Practical identifiability analysis of large environmental simulation models. Water Resour. Res. 2001, 37, 1015-1030.

46. Hornberger, G.M.; Spear, R.C. Eutrophication in peel inlet-I. The problem-defining behavior and a mathematical model for the phosphorus scenario. Water Res. 1980, 14, 29-42.

47. Spear, R.C.; Hornberger, G.M. Eutrophication in peel inlet-II. Identification of critical uncertainties via generalized sensitivity analysis. Water Res. 1980, 14, 43-49.

48. Beven, K.; Binley, A. The future of distributed models-Model calibration and uncertainty prediction. Hydrol. Process. 1992, 6, 279-298.

49. Bastidas, L.A.; Gupta, H.V.; Sorooshian, S.; Shuttleworth, W.J.; Yang, Z.L. Sensitivity analysis of a land surface scheme using multicriteria methods. J. Geophys. Res.-Atmos. 1999, 104, 19481-19490.

50. Blackwell, A.L.; Blackwell, C.C., Jr. Minimum sensitivity parameter estimation for dynamic ecosystem models1. In Developments in Environmental Modelling; William, K., Lauenroth, G.V.S., Marshall, F., Eds.; Elsevier: Amsterdam, The Netherlands, 1983; Volume 5, pp. 189-194. 
51. Loehle, C. A hypothesis testing framework for evaluating ecosystem model performance. Ecol. Modell. 1997, 97, 153-165.

52. Omlin, M.; Brun, R.; Reichert, P. Biogeochemical model of lake zurich: Sensitivity, identifiability and uncertainty analysis. Ecol. Model. 2001, 141, 105-123.

53. Meixner, T.; Gupta, H.V.; Bastidas, L.A.; Bales, R.C. Sensitivity analysis using mass flux and concentration. Hydrol. Process. 1999, 13, 2233-2244.

54. McIntyre, N.R.; Wagener, T.; Wheater, H.S.; Chapra, S.C. Risk-based modelling of surface water quality: A case study of the charles river, massachusetts. J. Hydrol. 2003, 274, 225-247.

55. Reckhow, K.H.; Chapra, S.C. Modeling excessive nutrient loading in the environment. Environ. Pollut. 1999, 100, 197-207.

(C) 2015 by the authors; licensee MDPI, Basel, Switzerland. This article is an open access article distributed under the terms and conditions of the Creative Commons Attribution license (http://creativecommons.org/licenses/by/4.0/). 